\title{
Validity of a computer-assisted manual segmentation software to quantify wrist erosion volume using computed tomography scans in rheumatoid arthritis
}

Fausto Salaffi ${ }^{1 *}$, Marina Carotti ${ }^{2}$, Alessandro Ciapetti ${ }^{1}$, Alarico Ariani ${ }^{1}$, Stefania Gasparini ${ }^{1}$ and Walter Grassi ${ }^{1}$

\begin{abstract}
Background: To investigate the performance of conventional radiography (CR) for the detection of bone erosions of wrist in rheumatoid arthritis (RA) using multidetector computed tomography (CT) as the reference method and to evaluate the validity of a computer-assisted manual segmentation (outlining) technique to quantify erosion volume on $\mathrm{CT}$ scans.

Methods: Twenty five RA patients and six controls underwent CT and radiographic evaluation of the dominant wrist on the same day. CT was performed by using a 64 GE light Speed VCT power. Wrists images were evaluated separately and scored for the presence of erosions according to the Outcome Measures in Rheumatology Rheumatoid Arthritis MRI Scoring System (RAMRIS) and the Sharp/van der Heijde scoring method. Measurements of bone erosion volumes were obtained using OsiriX medical imaging software. The mean value of the volumes of the $C T$ bone erosions detected at two readings was used to calculate inter-rater agreement.

Results: The overall sensitivity, specificity and accuracy of radiography for detecting erosions were $25.5 \%, 98.3 \%$ and $70.1 \%$, respectively. Using computer-assisted manual segmentation (outlining) technique, erosion volume on CT measurements per subject was ranged from $0.001 \mathrm{~cm}^{3}$ to $2.01 \mathrm{~cm}^{3}$. Spearman's RAMRIS score of each wrist bones in all subjects $(n=25)$ were correlated with the total erosion volume on $C T(p<0.0001)$, with the ratio between erosion volume and the corresponding bone volume on a percentage basis $(p<0.0001)$. The total Sharp/van der Heijde erosion score of the all wrist bones was correlate with the RAMRIS score $(p=0.008)$. The intraclass correlation coefficients (ICC) for manual segmentation showed high agreement $($ ICC $=0.901)$.

Conclusions: Considering $C T$ as the reference method, $C R$ showed very low sensitivity. A close correlation with $C T$ erosion volumes supports the OMERACT RAMRIS erosion score as a semiquantitative measure of joint damage in RA. Although the computer-assisted manual segmentation can be beneficial for diagnostic decision in crosssectional CT examinations of the wrist in RA, this technique will require further evaluation in terms of responsiveness.
\end{abstract}

Keywords: Rheumatoid arthritis, Bone erosion, Computed tomography, Conventional radiography, Computer-assisted manual segmentation technique

\footnotetext{
*Correspondence: fsalaff@tin.it

${ }^{1}$ Rheumatology Department, Politechnic University of the Marche, Ospedale

"C. Urbani", Via dei Colli, 52, Ancona, Jesi 60035, Italy

Full list of author information is available at the end of the article
} 


\section{Background}

The optimization of imaging measures is an important strategy for evaluating and monitoring bone damage in rheumatoid arthritis (RA) [1]. Although conventional radiography (CR) remains the cornerstone of imaging modalities in RA, computed tomography (CT) appear more sensitive for the detection of bone erosions in comparison to CR, magnetic resonance imaging (MRI) and ultrasonography (US). For that reason, CT can be considered the standard reference method for the detection of erosive bone destructions in early stage of the disease [2-6]. Current generation of ultrafast CTs allows acquiring highresolution volumetric data in few seconds and providing detailed anatomical informations. In particular, 3-D volume rendering techniques makes feasible to generate high-quality images, offering a realistic anatomical view of the body and organs from tomographic data.

Radiographic scores, such as the Larsen [7], Sharp scores and its modified versions [8,9], are standard methods to evaluate and monitor the joint damage in RA [10,11]. Despite considerable effort to either reduce or at least define the intrinsic limitations of radiographic scores, some problems remains, especially for the wrist's evaluation, such as reader variability, floor and ceiling effects [12-14] and inability to accurately quantify damage and its progression. To circumvent these problems, the feasibility of a computerized image analysis of erosion volumes of the hands has been evaluated. The computer system has been shown to provide reproducible data, but showed poor correlation with common standard scores used to define bone erosions [15-18]. Unlike the $\mathrm{CR}$, no method of qualitative score was developed specifically for CT images. Therefore, monitoring changes of the erosions volume is an important task for a correct evaluation of disease progression and response to treatment. Measurements of erosions volume by CT images has been described by Duryea et al. [19] and Døhn et al. [20]. In particular, Duryea et al. [19] have developed a semi-automated method for the evaluation of the profile of carpal bones and subsequent determination of the volume erosion by comparing the images obtained at baseline and subsequent checks.

The objectives of our study were to investigate the performance of the CR for the detection of bone erosions in the wrist of patients with RA, using multidetector $\mathrm{CT}$ as the reference method and to assess the validity of a computer-assisted manual segmentation software to quantify the erosion volume of wrist detected by CT.

\section{Methods}

\section{Patients}

Twenty five patients with RA (6 men and 19 women) with a median age of 54 years old (range 35-79 years old) and a mean disease duration of 18 months (range 11-24 months), fulfilling the American College of Rheumatology (ACR) 1987 criteria [21] and six healthy controls (volunteer medical doctor and nurses of the Radiology Department of the Politechnic University of Marche, Ancona, Italy) matched for age and gender, were included in the study. The study was approved by the local Institutional Research Ethics Committee (Comitato Etico dell'Azienda Sanitaria Unica Regionale di Ancona) and informed consent was obtained from all patients.

\section{Imaging}

The CR was performed at level of the dominant wrist in RA patients and healthy subjects, according posteroanterior and oblique projections. CT images were obtained in the same day by using a 64 GE light Speed VCT power (parameters: $90 \mathrm{kV}, 80 \mathrm{mAs}$, pitch $0.531 \mathrm{~mm}$, slice thickness of $0.625 \mathrm{~mm}$, slice spacing $0.4 \mathrm{~mm}$, gantry rotation time of $0.8 \mathrm{~s}$, without contrast medium). Patients were placed in a prone position with the arm stretched and the palm facing down for the CT examinations. Axial, coronal and sagittal reconstructions, with a slice thickness of $1.0 \mathrm{~mm}$, were created and used for images evaluation (Figure 1).

\section{Erosion score assessment}

Images obtained by $\mathrm{CR}$ and $\mathrm{CT}$ were evaluated for erosions, by a musculoskeletal radiologist (MC) experienced reader of the Outcome Measures in Rheumatology Rheumatoid Arthritis MRI Scoring (OMERACT RAMRIS) system, blinded to clinical and other imaging data. The presence and number of erosions of the dominant wrist were evaluated by $\mathrm{CR}$ and $\mathrm{CT}$ examining the following bones: scaphoid, lunate, triquetrum, pisisorm, trapezium, trapezoid, capitate, hamate, distal ulna, distal radius and metacarpal bases. A total of 375 bones were explored. The correct position of erosions was marked on scoring sheets. According to OMERACT criteria [22], erosions on CT were defined as a definite cortical break seen in two planes, with a cortical break (loss of cortex) seen in at least one plane. All three orthogonal planes were viewed to confirm the presence of erosion (Figure 1). Definitions and scorings of CT erosions were described by using the semiquantitative OMERACT RAMRIS [23,24]. The score for erosions were assigned considering the percentage of bone volume involved (score $0-10$, by $10 \%$ volume increments), leading to a total score ranging from 0 to 150 [23,25]. Erosions of dominant wrist evaluated by $\mathrm{CR}$ were scored by Sharp/van der Heijde method [9]. According this method the total erosion score of one wrist ranges from 0 to 75 . 


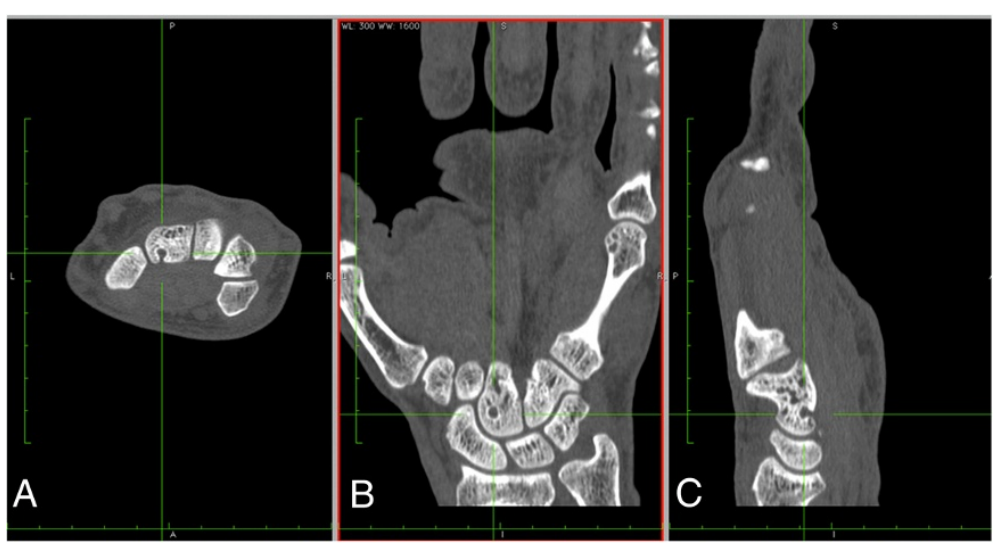

Figure 1 An example of bone erosion of the capitate bone seen on axial (A), coronal (B) and sagittal (C) CT reconstructions of wrist.

\section{Erosion volume measurements}

CT images were read by two rheumatologists (FS and AA) over four days by using a large-screen (27-inch) radiologic workstation monitor. Erosions volumes were calculated by a computer-assisted manual segmentation (outlining) technique using Osiri $X$ medical imaging software which is a fast DICOM viewer program for the Apple Macintosh, downloadable at the following Web site: www.osirix-viewer. com. The OsiriX program offers all the basic image manipulation functions of zoom, intensity adjustment and filtering with real-time performance [26]. Additional functions are accessible as well, such as multiplanar projections, convolution filters, variable slice thickness adjustments, minimum and maximum intensity projections, surface and volume rendering and number of slices to be reconstructed. Each erosion was outlined manually in coronal or axial slice. The outlining of erosion borders was done using a Bamboo Connect pen tablet system (Wacom Technology Corporation, Vancouver, WA, USA). The erosion area was then calculated by the computer software from multiple slices and multiplied by the slice thickness to provide the erosion volume. Further, the ratio between erosion volume $(\mathrm{eV})$ and the corresponding bone volume $(b V)$, on a percentage basis $(e \tilde{V} b V * 100)$ have been calculated as well. The mean of the two measurements were used for the analysis. The readers recorded the time consumed scoring each image set. The complete scoring of images from one patient took an average of $18 \mathrm{mi}-$ nutes (ranging from 13 to 48 minutes). Figure 2 give example of manual segmentation of the wrist erosions obtained in coronal projection. Figure 3 shows the calculation of volume erosion of the capitate bone seen in axial scan.

\section{Statistical analysis}

The specificity, sensitivity and accuracy of CR in detecting bone erosions, considering CT as the reference method, were calculated. Spearman's correlation coefficients between the OMERACT RAMRIS erosion scores, CT erosion volume and the radiographic Sharp/van der Heijde erosion score were obtained. Inter-rater reproducibility was calculated as the intraclass correlation coefficient (ICC) with absolute agreement followed by the $95 \%$ confidence intervals (95\% CI) in brackets. The mean value of the CT volumes found by two readers was used to calculate the inter-rater agreement. A Bland-Altman difference plot [27] was performed to compare the manual volume measurements. Wilcoxon Signed-Ranks Test was used to investigate significant differences between observers. MedCalc, version 12.0 for Windows (MedCalc Software, Ostend, Belgium) was used for statistical calculations and p value less than 0.05 was considered statistically significant.

\section{Results}

A total of 375 wrist bones were assessed for erosions in RA patients and 90 wrist bones in healthy controls. All patients had at least one erosion on CT, while none was seen in healthy controls. CT and CR detected 145 and 37 erosions, respectively. All erosions detected by CR were confirmed by CT. The lunate, trapezium, capitate and the first metacarpal head bones were common sites of erosions (Figure 4). Considering CT as the reference method, the sensitivity, specificity and overall accuracy of CR for detecting erosions were $25.5 \%, 98.3 \%$ and $70.1 \%$, respectively. Pattern differences between early and established disease were not detected.

The total erosion volume in each subject ranged from $0.001 \mathrm{~cm}^{3}$ to $2.01 \mathrm{~cm}^{3}$. The highest erosion volumes were noted in the capitate (highest value $0.42 \mathrm{~cm}^{3}$ ) and lunate (highest value $0.26 \mathrm{~cm}^{3}$ ) bones. Spearman's RAMRIS CT score of individual wrist bones in all patients, correlated with the erosion volume on CT (rho 0.823; p < 0.0001) and with the ratio between erosion volume and the corresponding bone volume on a percentage basis $(r h o=0.914$; $\mathrm{p}<0.0001)$. The total Sharp/van der Heijde erosion score of the all wrist bones was slight correlated with the 


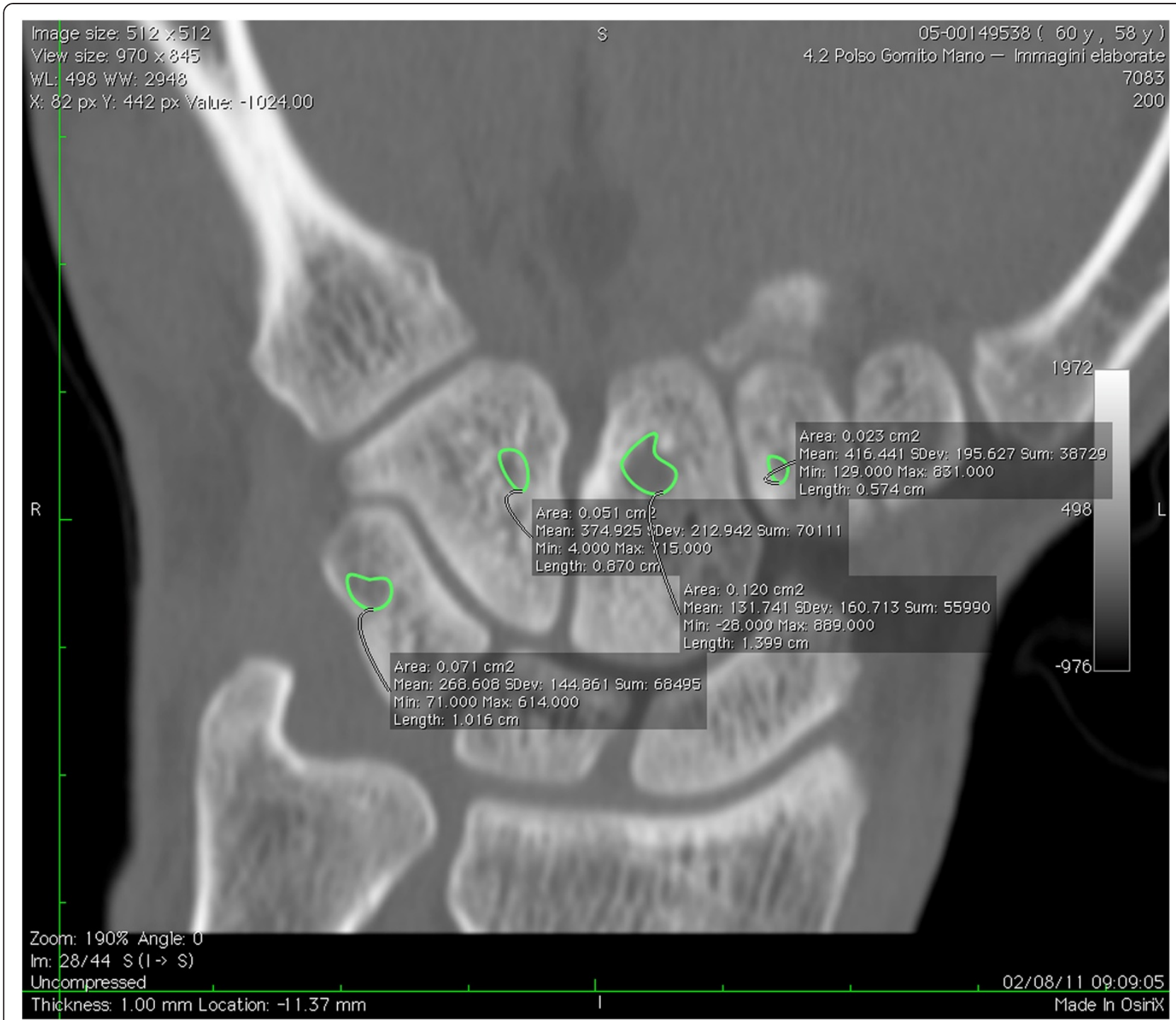

Figure $\mathbf{2}$ CT coronal reconstructions of wrist. Magnification of erosions of triquetrum, hamate, capitate and trapezoid. Each area was automatically obtained by defining the contour of the erosion.

RAMRIS CT score (rho 0.143; $\mathrm{p}=0.008$ ), but not with total volume erosion measurement on CT (rho 0.098; $P=$ 0.069). The ICC for manual segmentation showed very high precision (ICC $=0.901 ; 95 \%$ CI 0.882 to 0.931 ), with no significant difference in the inter-rater reproducibility. The mean and $95 \% \mathrm{CI}$ of the absolute difference between the volume measurements were 0.158 (95\% CI for the mean 0.105 to 0.211 ), and 0.165 (95\% CI for the mean 0.1081 to 0.222 ) $\mathrm{cm}^{3}$, respectively (difference $0.00924 ; 95 \%$ of difference -0.069 to 0.088 ), which are depicted graphically in the Bland-Altman difference plot of Figure 5.

\section{Discussion}

Considering the wrist frequently involved in RA $[28,29]$ and that anatomical damage at this level has a predictive significance of evolution of the disease, its evaluation assumes an important clinical significance [28-32]. The lunate, trapezium, capitate and the first metacarpal head bones are common sites of erosions. Østergaard et al [33] found that capitate, ulna, lunate, triquetrum, and scaphoid bones were the most frequently bone involved in a MRI datasets from 258 RA patients (126 early RA patients).

Experiences from comparative studies of CR, US, MRI and $\mathrm{CT}$ have shown that $\mathrm{CT}$ is the most sensitive imagine technique for the detection of bone erosions [2,3,34-38] and, therefore, can be considered the gold standard for the evaluation of wrist anatomical damage in RA. Difficulties of CR for a detail evaluation of wrist joints are mainly due to a projectional superimposition of bones in this complicated anatomical area, high irregularities of the bone margins (e.g. at level of 


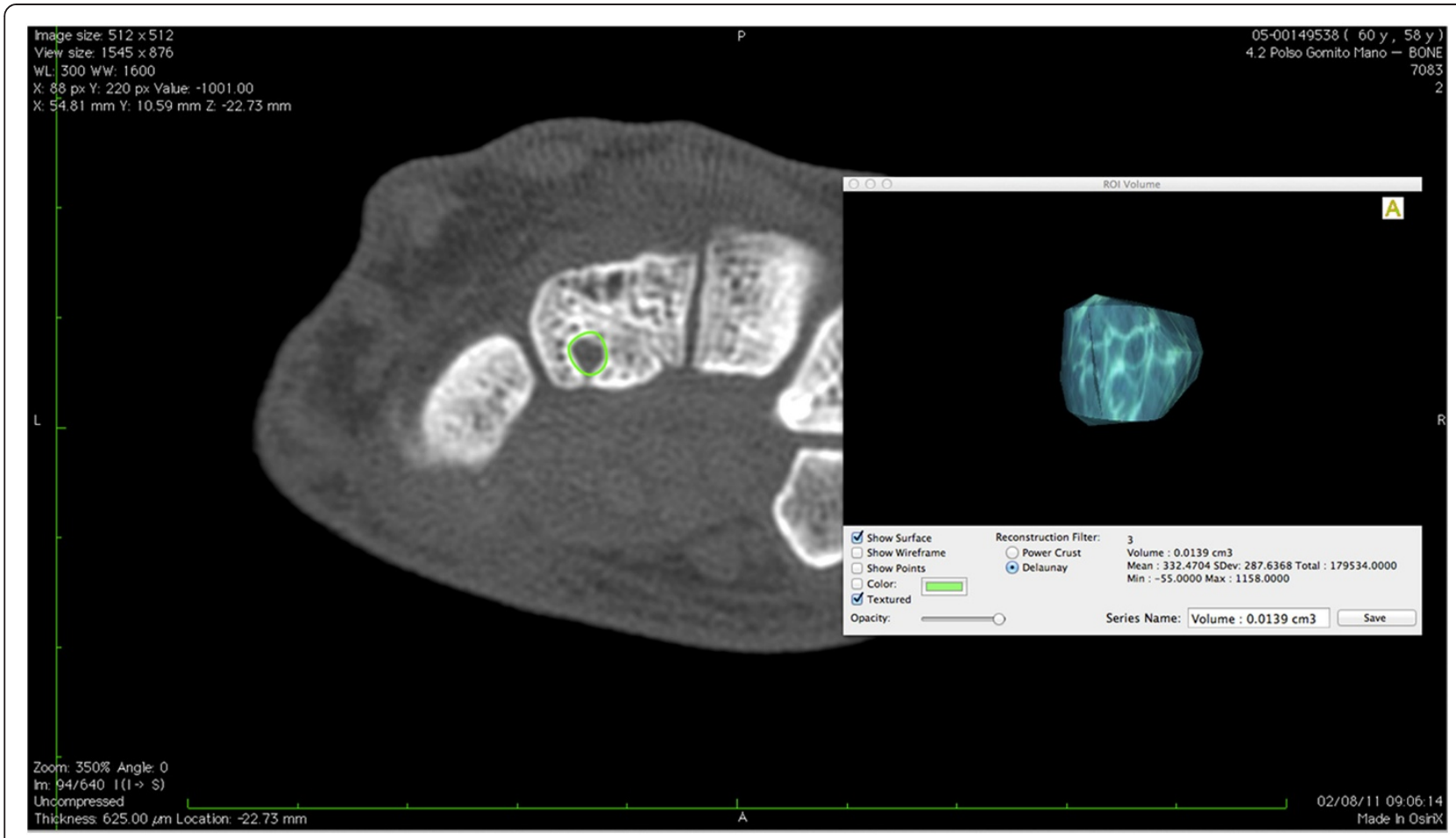

Figure $\mathbf{3}$ CT images of wrist. The erosion volume was obtained after the automatic calculation of the area of the erosion.

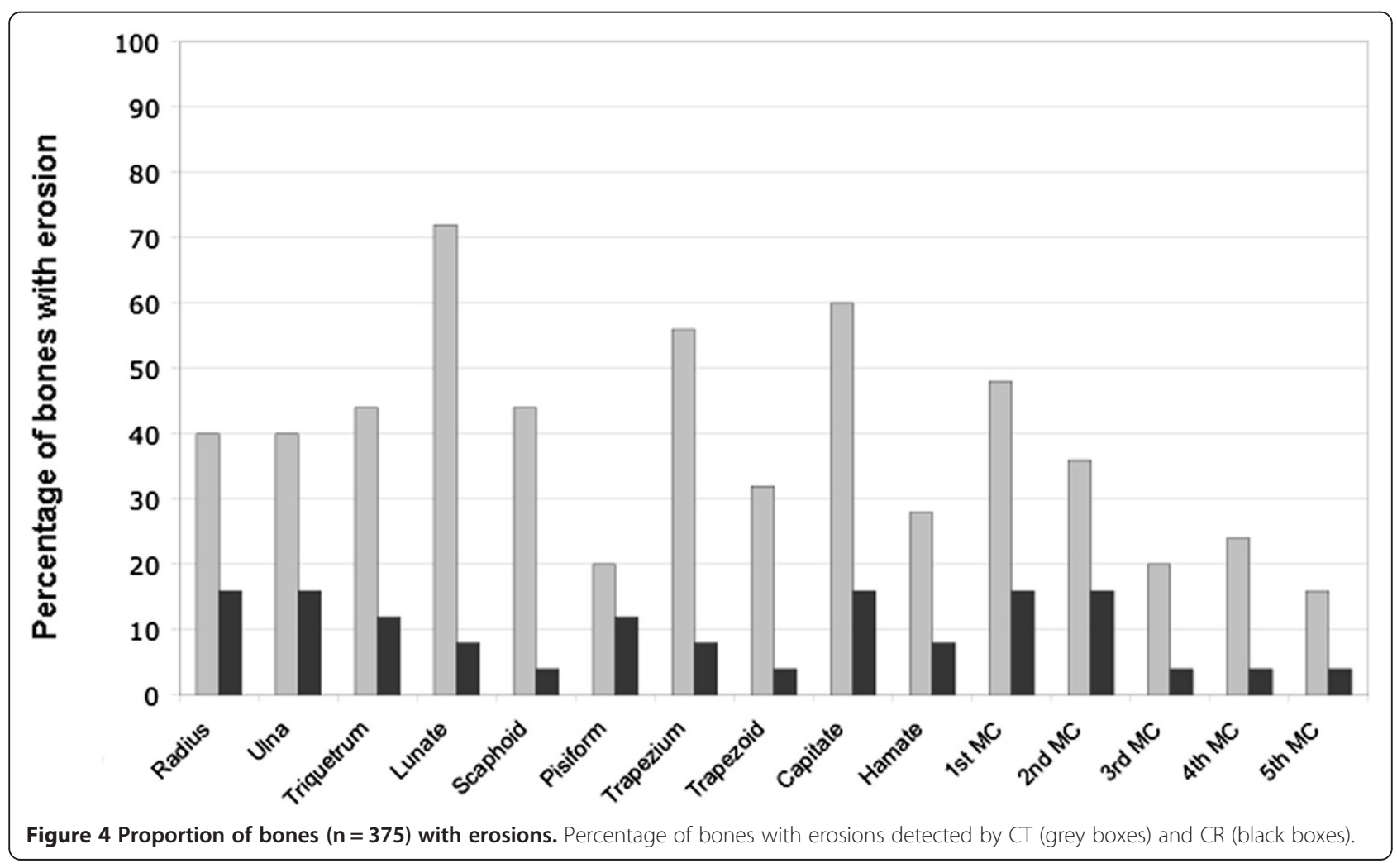




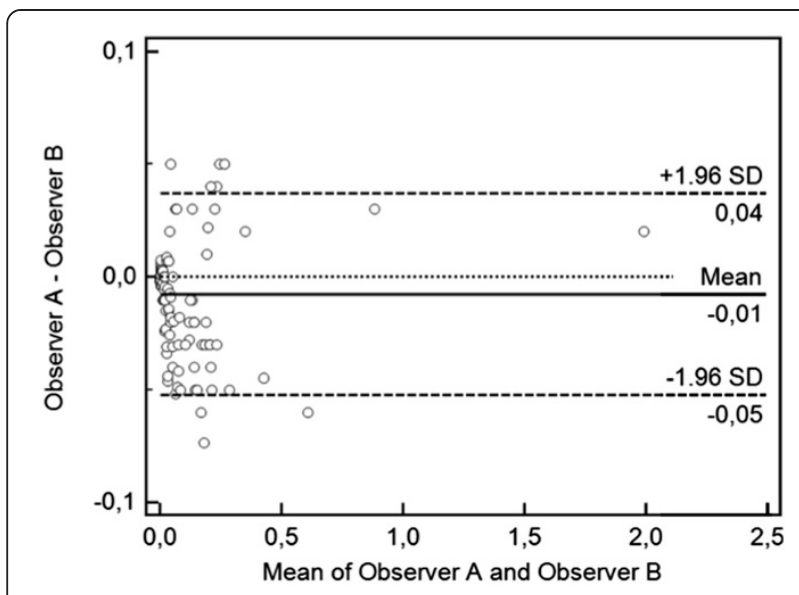

Figure 5 A Bland-Altman difference plot comparing computerassisted erosion volume measurements by two observers.

ligaments attachment) and the presence of nutritive foramina that can appear like erosions. These aspects make difficult the discrimination between normal anatomy and presence of erosions.

Measurements of erosion progression in patients with RA have generally relied upon semiquantitative scoring systems $[7,11,14]$. Despite considerable effort to either reduce or at least define the intrinsic limitations of radiographic scores, problems remain with reader variability and floor and ceiling effects [12-14]. Principles of OMERACT RA MRI system [23,24] were applied to score bone erosions by CT. Despite a scoring system for CT images is not yet available, we found OMERACT RA MRI system reasonable to use due to the similar tomographic visualization of joints on CT and MRI, the good inter-intraobserver reliability and a high level of sensitivity and specificity demonstrated by RAMRIS system in monitoring joint destruction in RA [39-41].

Recently, technological advances in CT imaging modalities and the introduction of $3 \mathrm{D}$ image reconstruction through computer systems, allowed the visualization of tiny defects of the wrist a feasible task [42]. High resolution CT systems are fast and produce high spatial resolution images with near isotropic voxels. Therefore, 3D image reconstruction of segmented carpals is significantly more accurate. The visualization and processing of 3D data require special navigation tools and multidimensional rendering software that are available on high end $3 \mathrm{D}$ rendering workstations that are most accessible in academic and specialized imaging centers.

The successful diffusion of OsiriX in the medical community [43] is mainly due to the fact that it is a cost effective alternative to not-free softwares and can be customized to match the needs and specific usage in clinical setups [26]. Previously published studies have investigated segmentation of the carpal bones of wrist by
CT scans with a variety of goals. Snel et al. [44,45] and Sebastian et al. [46] performed wrist segmentation to examine the kinematics of the carpal bones. Other studies have examined wrist scans as a validation of the general 3D segmentation methods. Van Cleynenbreugel et al. [47] and Yao et al. [48] described a semiautomatic method to segment bones on spiral CT scans. These techniques were developed to better understand carpal kinematics or as part of a more general 3D segmentation package. As the same Døhn et al. [49] and Bird et al. [50], we found that the volume measurements of erosions by CT was highly reproducible and closely correlated with the semiquantitative scores of bone erosions according to OMERACT RAMRIS system score. This aspect support the evidence for the semiquantitative MRI measures of erosion as a valid measure of bone destruction in RA. Although the volume measurement of erosion by CT has proved to yield reproducible findings, it showed poor correlation with joint space narrowing score [15] and with standard erosion score [18]. Since CT scanning appears more accurate than the observation of $2 \mathrm{D}$ images, this result can compromise the validity of the total Sharp/van der Heijde erosion score. However, the disadvantages of $\mathrm{CT}$ scanning are due to its relatively higher cost and risk of hazard from radiation exposure [51,52]. Further, our method evaluates 15 carpal sites in one shot, each of them potentially containing multiple erosions. A limited number of joints can be examined by using CT due to the exposure to ionizing radiation. Consequently, a smaller number of sites can be assessed by $\mathrm{CT}$ which potentially lead to a risk of missing signs of erosive progression of the disease. Additionally, the method could also be developed to measure erosion volumes in the proximal interphalangeal and metacarpophalangeal joints that are common sites of erosions as well.

These considerations could account for the poor correlation observed between the total Sharp/van der Heijde erosion score and the total erosion volume measurement on CT. This might reside in the fact that the first is a semiquantitative measure of the erosion based on the simple observation of two-dimensional images, while OsiriX allows to measure real volumes.

\section{Conclusions}

The number of erosions detected on CT indicates that this imaging modality is high sensitive for detecting bone erosions in wrist of RA patients. The close correlation with erosion volumes determined by CT provides further evidence for the semiquantitative OMERACT RAMRIS erosion score as a valid tool of anatomical bone damage evaluation. However, the sensitivity to change is not yet established and the disadvantages of CT include the necessity for ionising radiation and inability to visualize soft 
tissue. Moreover, the computer-assisted manual segmentation technique is complicated and time-consuming. The longer time for the volume calculations was largely due to the manual nature of the segmentation process as well as to the large number of bones assessed at level of wrist. Whether computer-assisted manual segmentation technique is sufficiently precise the evaluation of responsiveness has not yet been tested in our study and, therefore, it will be necessary to evaluate this aspect in further investigations on larger prospective studies.

\section{Abbreviations}

RA: Rheumatoid arthritis; CR: Conventional radiography; CT: Computed tomography; MRI: Magnetic resonance imaging; US: Ultrasonography; ACR: American College of Rheumatology (ACR); OMERACT RAMRIS: Outcome measures in rheumatology rheumatoid arthritis MRI scoring system; ICC: Intraclass correlation coefficient.

\section{Competing interests}

The authors declare that they have no competing interests.

\section{Authors' contributions}

FS contributed to the conception and design of the study, to perform the data analysis and was in charge of drafting and writing the manuscript. MC contributed to the conception and design of the study, to the acquisition of data and in writing the manuscript. AC contributed in writing the manuscript. AA contributed to acquisition of data; SG contributed to the acquisition of data. WG contributed in writing the manuscript. All the authors read and approved the final manuscript.

\section{Author details}

${ }^{1}$ Rheumatology Department, Politechnic University of the Marche, Ospedale "C. Urbani", Via dei Colli, 52, Ancona, Jesi 60035, Italy. ${ }^{2}$ Radiology Department, Politechnic University of the Marche, Ancona, Italy.

Received: 14 February 2013 Accepted: 3 September 2013

Published: 12 September 2013

\section{References}

1. Tan YK, Conaghan PG: Imaging in rheumatoid arthritis. Best Pract Res Clin Rheumatol 2011, 25(4):569-84.

2. Perry D, Stewart N, Benton N, Robinson E, Yeoman S, Crabbe J, McQueen F: Detection of erosions in the rheumatoid hand; a comparative study of multidetector computerized tomography versus magnetic resonance scanning. J Rheumatol 2005, 32:256-67.

3. Døhn UM, Ejbjerg B, Court-Payen M, Hasselquist M, Narvestad E, Szkudlarek M, Møller J, Thomsen HS, Østergaard M: Are bone erosions detected by magnetic resonance imaging and ultrasonography true erosions? A comparison with computed tomography in rheumatoid arthritis metacarpophalangeal joints. Arthritis Res Ther 2006, 8:R110.

4. Filippucci E, Meenagh G, Delle Sedie A, Salaffi F, Riente L, lagnocco A, Scirè CA, Montecucco C, Bombardieri S, Valesini G, Grassi W: Ultrasound imaging for the rheumatologist. XX. Sonographic assessment of hand and wrist joint involvement in rheumatoid arthritis: comparison between twoand three-dimensional ultrasonography. Clin Exp Rheumatol 2009, 27(2):197-200

5. Grassi W, Filippucci E, Carotti M, Salaffi F: Imaging modalities for identifying the origin of regional musculoskeletal pain. Best Pract Res Clin Rheumatol 2003, 17(1):17-32.

6. Grassi W, Filippucci E, Farina A, Salaffi F, Cervini C: Ultrasonography in the evaluation of bone erosions. Ann Rheum Dis 2001, 60(2):98-103.

7. Larsen A, Dale K, Eek M: Radiographic evaluation of rheumatoid arthritis and related conditions by standard reference films. Acta Radiol Diagn (Stockh) 1977, 18:481-91.

8. Scott D, Laasonen L, Priolo F, Houssein D, Bacarini L, Cerase A, Cammisa M: The radiological assessment of rheumatoid arthritis. Clin Exp Rheumatol 1997, 15(Suppl 17):S53-S61.
9. Van der Heijde D: How to read radiographs according to the Sharp/van der Heijde method. J Rheumatol 1999, 26:743-5.

10. Salaffi F, Carotti M, Ciapetti A, Gasparini S, Filippucci E, Grassi W: Relationship between time-integrated disease activity estimated by DAS28-CRP and radiographic progression of anatomical damage in patients with early rheumatoid arthritis. BMC Musculoskelet Disord 2011, 30:120.

11. Salaffi F, Carotti M, Lamanna G, Baldelli S: Quantitative analysis of radiologic progression in rheumatoid arthritis: controversies and perspectives. Radiol Med 1997, 93(3):174-84.

12. Salaffi F, Carotti M: Interobserver variation in quantitative analysis of hand radiographs in rheumatoid arthritis: comparison of 3 different reading procedures. J Rheumatol 1997, 24(10):2055-6.

13. van der Heijde DM: Plain X-rays in rheumatoid arthritis: overview of scoring methods, their reliability and applicability. Baillieres Clin Rheumatol 1996, 10:435-53.

14. Boini S, Guillemin F: Radiographic scoring methods as outcome measures in rheumatoid arthritis: properties and advantages. Ann Rheum Dis 2001, 60:817-27.

15. Angwin J, Heald G, Lloyd A, Howland K, Davy M, James MF: Reliability and sensitivity of joint space measurements in hand radiographs using computerized image analysis. J Rheumatol 2001, 28:1825-36.

16. Higgs JB, Smith D, Rosier KFD, Charlesworth RW: Quantitative measurement of erosion growth and joint space loss in rheumatoid arthritis hand radiographs. J Rheumatol 1996, 23:265-72.

17. Angwin J, Lloyd A, Heald G, Nepom G, Binks M, James MF: Radiographic hand joint space width assessed by computer is a sensitive measure of change in early rheumatoid arthritis. J Rheumatol 2004, 31:1050-61.

18. Sharp JT, Gardner JC, Bennett EM: Computer-based methods for measuring joint space and estimating erosion volume in the finger and wrist joints of patients with rheumatoid arthritis. Arthritis Rheum 2000, 43:1378-86.

19. Duryea J, Magalnick M, Alli S, Yao L, Wilson M, Goldbach-Mansky R: Semiautomated three dimensional segmentation software to quantify carpal bone volume changes on wrist CT scans for arthritis assessment. Med Phys 2008, 35:2321-30.

20. Døhn UM, Boonen A, Hetland ML, Hansen MS, Knudsen LS, Hansen A, Madsen OR, Hasselquist M, Møller JM, Østergaard M: Erosive progression is minimal, but erosion healing rare, in rheumatoid arthritis patients treated with adalimumab. a 1 year investigator-initiated follow- up study using high-resolution computed tomography as the primary outcome measure. Ann Rheum Dis 2009, 68:1585-90.

21. Arnett FC, Edworthy SM, Bloch DA, McShane DJ, Fries JF, Cooper NS, Healey LA, Kaplan SR, Liang MH, Luthra HS, et al: The American Rheumatism Association 1987 revised criteria for the classification of rheumatoid arthritis. Arthritis Rheum 1988, 31:315-24.

22. Ejbjerg B, McQueen F, Lassere $M$, Haavardsholm E, Conaghan $P$, O'Connor $P$, Bird P, Peterfy C, Edmonds J, Szkudlarek M, Genant H, Emery P, Østergaard $M$ : The EULAR-OMERACT rheumatoid arthritis MRI reference image atlas: the wrist joint. Ann Rheum Dis 2005, 64(Suppl 1):i23-47.

23. Østergaard M, Peterfy C, Conaghan P, McQueen F, Bird P, Ejbjerg B, Shnier R, O'Connor P, Klarlund M, Emery P, Genant H, Lassere M, Edmonds J: OMERACT Rheumatoid Arthritis Magnetic Resonance Imaging Studies. Core set of MRI acquisitions, joint pathology definitions, and the OMERACT RA-MRI scoring system. J Rheumatol 2003, 30:1385-6.

24. Conaghan P, Bird P, Ejbjerg B, O'Connor P, Peterfy C, McQueen F, Lassere M, Emery P, Shnier R, Edmonds J, Østergaard M: The EULAR-OMERACT rheumatoid arthritis $\mathrm{MRI}$ reference image atlas: the metacarpophalangeal joints. Ann Rheum Dis 2005, 64(Suppl 1): i11-i21.

25. Østergaard M, Edmonds J, McQueen F, Peterfy C, Lassere M, Ejbjerg B, Bird P, Emery P, Genant H, Conaghan P: The EULAR-OMERACT rheumatoid arthritis MRI reference image atlas. Ann Rheum Dis 2005, 64(Suppl 1):i2-i55.

26. Rosset A, Spadola L, Ratib O: OsiriX: an open-source software for navigating in multidimensional DICOM images. J Digit Imaging 2004, 17(3):205-16.

27. Bland JM, Altman DG. Statistical methods for assessing agreement between two methods of clinical measurement. Lancet 1986, 1:307-10.

28. Leak RS, Rayan GM, Arthur RE: Longitudinal radiographic analysis of rheumatoid arthritis in the hand and wrist. J Hand Surg 2003, 28:427-34

29. Ejbjerg BJ, Vestergaard A, Jacobsen S, Thomsen HS, Østergaard M: The smallest detectable difference and sensitivity to change of magnetic 
resonance imaging and radiographic scoring of structural joint damage in rheumatoid arthritis finger, wrist, and toe joints: a comparison of the OMERACT rheumatoid arthritis magnetic resonance imaging score applied to different joint combinations and the Sharp/van der Heijde radiographic score. Arthritis Rheum 2005, 52:2300-6.

30. Østergaard M, Hansen M, Stoltenberg M, Jensen KE, Szkudlarek M, Pedersen-Zbinden B, Lorenzen I: New radiographic bone erosions in the wrists of patients with rheumatoid arthritis are detectable with magnetic resonance imaging a median of two years earlier. Arthritis Rheum 2003, 48(8):2128-31.

31. McQueen FM, Stewart N, Crabbe J, Robinson E, Yeoman S, Tan PLJ, McLean L: Magnetic resonance imaging of the wrist in early rheumatoid arthritis reveals progression of erosions despite clinical improvement. Ann Rheum Dis 1999, 58:156-63.

32. Haavardsholm EA, Boyesen P, Østergaard M, Schildvold A, Kvien TK: Magnetic resonance imaging findings in 84 early rheumatoid arthritis patients: bone marrow edema predicts erosive progression. Ann Rheum Dis 2008, 67:794-800.

33. Østergaard M, Møller Døhn U, Duer-Jensen A, Hetland ML, Hørslev-Petersen K, Stengaard-Pedersen K, Junker P, Pødenphant J, Ejbjerg B: Patterns of magnetic resonance imaging bone erosion in rheumatoid arthritis-which bones are most frequently involved and show the most change? J Rheumatol 2011, 38(9):2014-7.

34. Savnik A, Malmskov H, Thomsen HS, Graff LB, Nielsen H, DanneskioldSamsoe $B$, et al: Magnetic resonance imaging of the wrist and finger joints in patients with inflammatory joint diseases. J Rheumatol 2001, 28:2193-200.

35. Klarlund M, Østergaard M, Jensen KE, Madsen JL, Skjodt H, Lorenzen I: Magnetic resonance imaging, radiography, and scintigraphy of the finger joints: one year follow up of patients with early arthritis. The TIRA Group. Ann Rheum Dis 2000, 59:521-8.

36. Møller Døhn U, Ejbjerg B, Court-Payen M, Hasselquist M, Narvestad E, Szkudlarek M, Møller JM, Thomsen HS, Østergaard M: Are bone erosions detected by magnetic resonance imaging and ultrasonography true erosions? A comparison with computed tomography in rheumatoid arthritis metacarpophalangeal joints. Arthritis Res Ther 2006, 8:R110.

37. Backhaus M, Kamradt T, Sandrock D, Loreck D, Fritz J, Wolf KJ,Raber H, Hamm B, Burmester GR, Bollow M: Arthritis of the finger joints: a comprehensive approach comparing conventional radiography, scintigraphy, ultrasound, and contrast-enhanced magnetic resonance imaging. Arthritis Rheum 1999, 42:1232-45.

38. Conaghan PG, O'Connor P, McGonagle D, Astin P, Wakefield RJ, Gibbon WW, Quinn M, Karim Z, Green MJ, Proudman S, Isaacs J, Emery $P$ : Elucidation of the relationship between synovitis and bone damage: a randomized magnetic resonance imaging study of individualjoints in patients with early rheumatoid arthritis. Arthritis Rheum 2003, 48:64-71.

39. Haavardsholm EA, Ostergaard M, Ejbjerg BJ, Kvan NP, Uhlig TA, Lilleås FG, Kvien TK: Reliability and sensitivity to change of the OMERACT rheumatoid arthritis magnetic resonance imaging score in a multireader, longitudinal setting. Arthritis Rheum 2005, 52(12):3860-7.

40. Conaghan PG, Ejbjerg B, Lassere M, Bird P, Peterfy C, Emery P, McQueen F, Haavardsholm E, O'Connor P, Edmonds J, Genant H, Østergaard M: A multicenter reliability study of extremity-magnetic resonance imaging in the longitudinal evaluation of rheumatoid arthritis. J Rheumatol 2007, 34(4):857-8.

41. Albrecht A, Finzel S, Englbrecht M, Rech J, Hueber A, Schlechtweg P, Uder M, Schett G: The structural basis of MRI bone erosions: an assessment by microCT. Ann Rheum Dis 2013, 72(8):1351-7.

42. Sunagawa $T$, Ishida $O$, Ishiburo M: Three-dimensional computed tomography imaging: its applicability in the evaluation of extensor tendons in the hand and wrist. J Comput Assist Tomogr 2005, 29:94-8.

43. Kim G, Jung HJ, Lee HJ, Lee JS, Koo S, Chang SH: Accuracy and reliability of length measurements on three-dimensional computed tomography using open-source OsiriX software. J Digit Imaging 2012, 25(4):486-91.

44. Snel JG, Venema HW, Moojen TM, Ritt JP, Grimbergen CA, den Heeten GJ. Quantitative in vivo analysis of the kinematics of carpal bones from three-dimensional CT images using a deformable surface model and a three-dimensional matching technique. Med Phys 2000, 27:2037-47.
45. Snel JG, Venema HW, Grimbergen CA: Deformable triangular surfaces using fast 1-D radial Lagrangian dynamics - segmentation of 3-D MR and CT images of the wrist. IEEE Trans Med Imaging 2002, 21:888-903.

46. Sebastian TB, Tek H, Crisco JJ, Kimia BB: Segmentation of carpal bones from CT images using skeletally coupled deformable models. Med Image Anal 2003, 7:21-45.

47. van Cleynenbreugel J, Kratka D, Berben L, Smet MH, Marchal G, Suetens P: A semiautomatic three-dimensional segmentation method for disarticulation of bone structures on spiral computed tomography images. J Digit Imaging 1995, 8:156-61.

48. Yao W, Abolmaesumi P, Greenspan M, Ellis RE: An estimation/correction algorithm for detecting bone edges in CT images. IEEE Trans Med Imaging 2005, 24:997-1010.

49. Døhn UM, Ejbjerg BJ, Hasselquist M, Narvestad E, Court-Payen M, Szkudlarek M, Møller J, Thomsen HS, Ostergaard M: Rheumatoid arthritis bone erosion volumes on CT and MRI: reliability and correlations with erosion scores on CT, MRI and radiography. Ann Rheum Dis 2007, 66(10):1388-1392.

50. Bird P, Lassere M, Shnier R, Edmonds J: Computerized measurement of magnetic resonance imaging erosion volumes in patients with rheumatoid arthritis: a comparison with existing magnetic resonance imaging scoring systems and standard clinical outcome measures. Arthritis Rheum 2003, 48(3):614-624.

51. Picano E, Matucci-Cerinic M: Unnecessary radiation exposure from medical imaging in the rheumatology patient. Rheumatology (Oxford) 2011, 50(9):1537-1539.

52. Hillman BJ, Goldsmith JC: The uncritical use of high-tech medical imaging. N Engl J Med 2010, 363(1):4-6.

doi:10.1186/1471-2474-14-265

Cite this article as: Salaffi et al:: Validity of a computer-assisted manual segmentation software to quantify wrist erosion volume using computed tomography scans in rheumatoid arthritis. BMC

Musculoskeletal Disorders 2013 14:265.

\section{Submit your next manuscript to BioMed Central and take full advantage of:}

- Convenient online submission

- Thorough peer review

- No space constraints or color figure charges

- Immediate publication on acceptance

- Inclusion in PubMed, CAS, Scopus and Google Scholar

- Research which is freely available for redistribution 